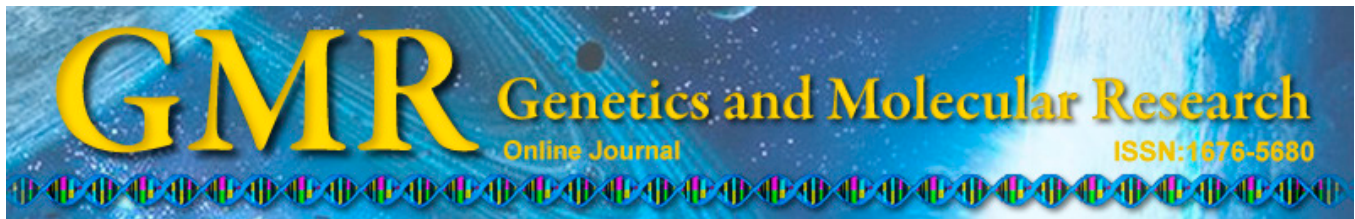

\title{
Identification of single nucleotide polymorphisms of the signal transducer and activator of transcription 3 gene (STAT3) associated with body measurement and carcass quality traits in beef cattle
}

\author{
N. Song ${ }^{1 *}$, L.S. Gui ${ }^{1 *}$, H.C. Xu ${ }^{1}$, S. Wu ${ }^{1}$ and L.S. Zan ${ }^{1,2}$ \\ ${ }^{1}$ College of Animal Science and Technology, Northwest A\&F University, \\ Yangling, Shaanxi, China \\ ${ }^{2}$ National Beef Cattle Improvement Center of Northwest A\&F University, \\ Yangling, Shaanxi, China \\ *These authors contributed equally to this study. \\ Corresponding author: L.S. Zan \\ E-mail: zanlinsen@163.com
}

Genet. Mol. Res. 14 (3): 11242-11249 (2015)

Received February 10, 2015

Accepted May 15, 2015

Published September 22, 2015

DOI http://dx.doi.org/10.4238/2015.September.22.18

\begin{abstract}
Previous studies have shown that the signal transducer and activator of transcription 3 gene (STAT3) is involved in lipid storage and energy metabolism, suggesting that STAT3 is a potential candidate gene that affects body measurement and carcass quality traits in animals. Therefore, the aim of this study was to identify polymorphisms in bovine STAT3 and to analyze their possible associations with body measurement and carcass quality traits in 493 individuals of 2 native Chinese cattle breeds: Qinchuan $(\mathrm{N}=371)$ and Jiaxian cattle $(\mathrm{N}=122)$. DNA sequencing and polymerase chain reaction-restriction fragment
\end{abstract}


length polymorphism (PCR-RFLP) were employed to detect STAT3 single nucleotide polymorphisms (SNPs). We found 5 SNPs: 1 in an exon (g.65812G $>$ A: exon 16) and 4 in introns (g.43591G $>$ A: 13 intron, g.67492T $>$ G: 19 intron, g.67519T $>$ C: 19 intron, and g.68964G $>$ A: 20 intron). Both g.65812G $>$ A and g. $68964 \mathrm{G}>\mathrm{A}$ were not in HardyWeinberg equilibrium (HWE), whereas individual frequencies of each genotype were consistent with HWE for other SNPs in Qinchuan cattle populations. For the Jiaxian cattle, the genotype distributions of the 4 mutations were in HWE except for g.67519T $>$ C. The results indicate that these SNPs have a significant association with some body measurements and carcass quality traits $(\mathrm{P}<0.05$ or $\mathrm{P}<0.01)$. Therefore, STAT3 might have potential effects on production traits in beef cattle populations and could be used for marker-assisted selection.

Key words: STAT3; SNP; Body measurement traits; Carcass quality traits

\section{INTRODUCTION}

Signal transducer and activator of transcription (STAT) belongs to a family of latent cytoplasmic transcription factors that convey signals from the cell membrane to the nucleus (Schust et al., 2006). They control key cellular and physiological processes, and have roles in immune regulation, apoptosis, lipid metabolism, and colorectal cancer (Dinasarapu et al., 2013). Seven STAT family members (STAT1, 2, 3, 4, 5a, 5b, and 6) have been identified in mammals (Lidija, 2013). Each of them is activated by specific extracellular ligands, including cytokines, growth factors, and hormones (Darnell, 1997; Levy and Darnell, 2002). Janus kinases (JAKs) have tyrosine kinase activity and can bind certain cell-surface cytokines (Liu et al., 2012a). Binding of ligands to receptors leads to the activation of JAKs, which can directly phosphorylate STATs and subsequently activate the transcription of target genes (Yang and George, 2008). STAT3, a transcription factor expressed in proliferating pre-adipocytes and adipocytes (Deng et al., 2000), is activated through phosphorylation of a single tyrosine (T705) in response to stimulation with cytokines, growth factors, or nutrients (Turkson and Jove, 2000). Phosphorylated STAT3 undergoes homo-dimerization and translocates to the nucleus, where it can bind to DNA and regulate the transcription of specific genes (Sen et al., 2009), such as PPAR $\gamma$, PRDM16, and C/EBP $\beta$. Zhang et al. (2011) demonstrated that the JAK2 inhibitor AG490 and siRNA could partially inhibit STAT3 activation and inhibit differentiation of 3T3-L1 adipocytes (Zhang et al., 2011). In these processes, STAT3 interacts with C/ EBP $\beta$ by binding the distal region of the C/EBP $\beta$ promoter at the early stage of adipogenesis. Treatment of 3T3-L1 pre-adipocytes with troglitazone (a synthetic PPAR $\gamma$ agonist) abolished STAT3-inhibitor and RNAi-mediated suppression of adipogenesis, suggesting that STAT3 regulates adipocyte differentiation via PPAR $\gamma$ (Wang et al., 2010). Mice lacking the JAK tyrosine kinase member Tyk2 became progressively obese due to aberrant development of Myf5+ brown adipose tissue (BAT). However, the constitutively active form of STAT3 could enhance stability of PRDM16 protein, leading to improved BAT development, normal levels of insulin, and significantly lower body weights in Tyk2-/- mice (Derecka et al., 2012). Studies using Ras-transformed mouse embryonic fibroblasts showed that ATP production was restricted in the absence of STAT3, suggesting that mitochondrial STAT3 is closely associated with cellular 
ATP levels (Gough et al., 2009). Taken together, these findings suggest that STAT3 might be a potential candidate gene for the selection of growth-related traits in livestock.

Since there are no reports of associations between STAT3 variants and body measurement and carcass quality traits in herbivore breeding, the current study was designed to detect the genetic variation of STAT3 in 493 Chinese cattle, and to explore the possible genetic association between variants of STAT3 and body measurement and carcass quality traits, which will benefit cattle breeding and genetics.

\section{MATERIAL AND METHODS}

\section{Animals, DNA samples, and data collection}

Blood samples were obtained from 493 individuals (unrelated for at least 3 generations) of 2 native Chinese cattle breeds: Qinchuan (371) and Jiaxian cattle (122). In this study, the Qinchuan animals were from the National Beef Cattle Improvement Center's experimental farm (Yangling Shaanxi, China), and the Jiaxian animals were from the Jiaxian Cattle breeding farm (Jiaxian County, Henan Province, China).

Genomic DNA of 493 cattle was isolated from blood samples treated with 2\% heparin, according to the standard phenol chloroform protocol, and stored at $-80^{\circ} \mathrm{C}$. DNA content was estimated spectrophotometrically, and then the DNA was diluted to $50 \mathrm{ng} / \mu \mathrm{L}$. All the DNA samples were stored at $-20^{\circ} \mathrm{C}$ for subsequent analysis.

We quantified the body measurement (body length, withers height, and chest circumference) and carcass quality (backfat thickness, ultrasound loin muscle area, and intramuscular fat content) traits of 371 Qinchuan cattle.

\section{Genotyping}

Primers used to amplify bovine STAT3 were designed from a published gene sequence (GenBank accession No. XM_010816228.1; Table 1). PCR amplification was performed in a $20-\mu \mathrm{L}$ volume mixture containing $50 \mathrm{ng} \mathrm{DNA}, 10 \mathrm{pM}$ of each primer, $1 \mathrm{X}$ buffer (including 1.5 $\mathrm{mM} \mathrm{MgCl}$ ), $200 \mathrm{uM}$ dNTPs, and 0.5 U Taq DNA polymerase (TaKaRa, Shiga, Japan). PCR conditions were as follows: $5 \mathrm{~min}$ at $94^{\circ} \mathrm{C}$ for $5 \mathrm{~min}, 35$ cycles at $94^{\circ} \mathrm{C}$ for $30 \mathrm{~s}$, annealing for $30 \mathrm{~s}, 72^{\circ} \mathrm{C}$ for $35 \mathrm{~s}$, and a final extension of $10 \mathrm{~min}$ at $72^{\circ} \mathrm{C}$.

Single nucleotide polymorphisms (SNPs) were identified through DNA sequencing of different regions. A DNA pool ( $30 \mathrm{ng} / \mu \mathrm{L}$ per cow) was constructed from 30 cows selected randomly, which had no genetic relationship, and was used as a template to amplify different regions of STAT3. DNA sequencing was carried out to screen variations within the amplified regions of the DNA pools constructed, and the products amplified from genomic DNA were directly sequenced in both directions. Sequences were analyzed with the DNASTAR software (Version.7.0).

Five SNPs (g.43591G >A, g.65812G $>$ A, g.67492T $>$ G, g.67519T $>$ C, and g.68964G $>$ A) were detected and are illustrated in Figure 1. According to the sequence mutations, the PCR products could be digested with Lpnp1, Tai1, Bse11, Nco1, and BspAC1 restriction enzymes to genotype the individuals. Aliquots of $10 \mu \mathrm{L}$ PCR products were digested with $10 \mathrm{U}$ Lpnp1 
(g.43591G>A), Tai1 (g.65812G >A), Bse11 (g.67492T>G), Nco1 (g.67519T>C), and BspAC1 (g.68964G $>$ A) for $5 \mathrm{~h}$ at $37^{\circ} \mathrm{C}$, respectively. The digested products were detected by electrophoresis on a $2.5 \%$ agarose gel stained with ethidium bromide.

\begin{tabular}{|c|c|c|c|c|}
\hline Amplified region & Primer & & $\operatorname{Tm}\left({ }^{\circ} \mathrm{C}\right)$ & Size (bp) \\
\hline Exon 16 & Primer A & $\begin{array}{l}\text { F: 5'-CCCCTTGGATTGAGAGTC-3' } \\
\text { R: 5'-CCTCTTTACTTTCCAATCTC-3' }\end{array}$ & 51.6 & 175 \\
\hline Intron 13 & Primer B & $\begin{array}{l}\text { F: 5'-GTGAACTTTTTCACCAAACC-3' } \\
\text { R: 5'-TTGCTCAGTCAACTTTCC-3' }\end{array}$ & 57.6 & 221 \\
\hline Intron 19 & Primer C & $\begin{array}{l}\text { F: 5'-TGGCAGCCCCCATCAGAAC-3' } \\
\text { R: 5'-GTATCCAGATTCCACCAGCAG-3' }\end{array}$ & 55.9 & 436 \\
\hline Intron 20 & Primer D & $\begin{array}{l}\text { F: 5'-TGGCAGCCCCCATCAGAAC-3' } \\
\text { R: 5'-GTATCCAGATTCCACCAGCAG-3' }\end{array}$ & 55.0 & 382 \\
\hline
\end{tabular}

$\mathrm{Tm}=$ melting temperature.
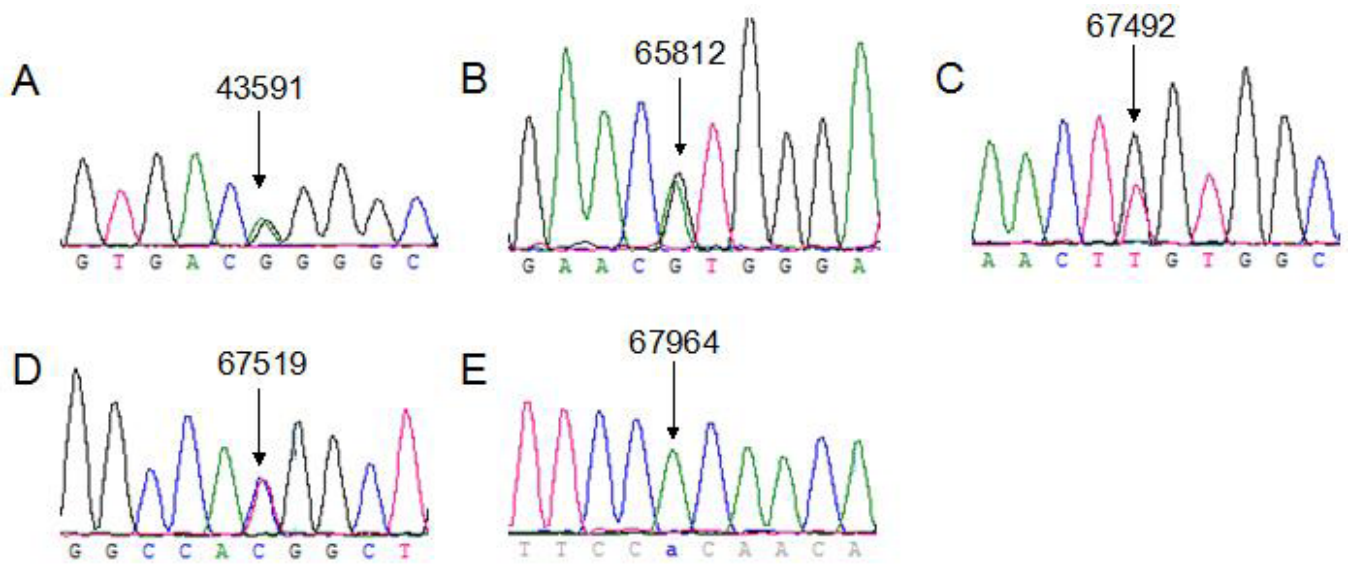

Figure 1. Sequencing maps of STAT3 gene SNPs in beef cattle. A. g.43591G $>$ A; B. g.65812G $>$ A; C. g.67492T $>$ G; D. g.67519T $>$ C; E. g.68964G $>$ A.

\section{Statistical analysis}

Genetic diversity parameters including genotype frequencies, heterozygosity $\left(H_{\mathrm{E}}\right)$, Hardy-Weinberg equilibrium (HWE), and polymorphism information content (PIC) were calculated using the Popgen 32 software, and they are summarized in Table 2.

To investigate the association of STAT3 genotypes with growth and carcass traits, general linear models were generated with the SPSS software (Version. 16.0). The following statistical linear model was used: $\mathrm{Yi}=\mu+\mathrm{Gi}+\mathrm{Ai}+\mathrm{Eik}$, where $\mathrm{Yi}$ was the traits measured for each of the individual cattle, $\mu$ was the overall population mean for the traits, $G i$ was the fixed effect associated with the genotype, $A i$ was the fixed effect due to age, and Eik was the standard error. 
Table 2. Genotype frequencies, $H_{\mathrm{E}}$, HWE, and PIC of the STAT3 gene SNPs in a Qinchuan cattle population.

\begin{tabular}{|c|c|c|c|c|c|c|c|c|}
\hline SNPs & Breeds & No. & & Frequencies & & $H_{\mathrm{E}}$ & $\chi^{2}(\mathrm{HWE})$ & PIC \\
\hline g.43591G $>A$ & QC & 371 & $0.46(\mathrm{GG})$ & 0.28 (GA) & $0.26(\mathrm{AA})$ & 0.48 & $>0.05$ & 0.36 \\
\hline g. $65812 \mathrm{G}>\mathrm{A}$ & & & $0.55(\mathrm{GG})$ & 0.35 (GA) & 0.10 (AA) & 0.40 & 4.18 & 0.32 \\
\hline g. $67492 \mathrm{~T}>\mathrm{G}$ & & & $0.38(\mathrm{TT})$ & $0.36(\mathrm{TG})$ & $0.26(\mathrm{GG})$ & 0.49 & $>0.05$ & 0.37 \\
\hline g. $67519 \mathrm{~T}>\mathrm{C}$ & & & $0.12(\mathrm{TT})$ & 0.23 (TC) & 0.65 (CC) & 0.36 & $>0.05$ & 0.29 \\
\hline g. $67964 \mathrm{G}>\mathrm{A}$ & & & $0.54(\mathrm{GG})$ & 0.38 (GA) & 0.08 (AA) & 0.39 & 0.65 & 0.32 \\
\hline g. $43591 \mathrm{G}>A$ & JX & 122 & $0.60(\mathrm{GG})$ & 0.26 (GA) & 0.14 (AA) & 0.39 & $>0.05$ & 0.32 \\
\hline g. $65812 \mathrm{G}>\mathrm{A}$ & & & $0.52(\mathrm{GG})$ & $0.23(\mathrm{GA})$ & $0.25(\mathrm{AA})$ & 0.46 & $>0.05$ & 0.35 \\
\hline g. $67492 \mathrm{~T}>\mathrm{G}$ & & & $0.32(\mathrm{TT})$ & 0.31 (TG) & 0.37 (GG) & 0.50 & $>0.05$ & 0.37 \\
\hline g. $67519 \mathrm{~T}>\mathrm{C}$ & & & $0(\mathrm{TT})$ & 0.28 (TC) & $0.72(\mathrm{CC})$ & 0.24 & 3.20 & 0.21 \\
\hline g. $67964 \mathrm{G}>\mathrm{A}$ & & & $0.56(\mathrm{GG})$ & 0.44 (GA) & $0(\mathrm{AA})$ & 0.34 & $>0.05$ & 0.29 \\
\hline
\end{tabular}

\section{RESULTS}

\section{SNPs identified}

Bovine STAT3 is located on chromosome 19, and it contains 23 exons encoding 1386 amino acids. In the present study, 5 variations including 1 mutation in an exon (g.65812G $>$ A: exon 16) and 4 non-coding mutations in an intron (g.43591G $>$ A: 13 intron, g.67492T $>$ G: 19 intron, g.67519T $>$ C: 19 intron and g.68964G $>$ A: 20 intron) were revealed by comparing the sequencing results with the DNA sequence of STAT3 published in GenBank. PCR-RFLP and DNA sequencing were used for further genotyping.

g.43591G>A, genotyped by Lpnp1 endonuclease, showed one 175-bp fragment for GG, 3 fragments $(175,135$, and $40 \mathrm{bp})$ for GA, and 2 fragments (135 and $40 \mathrm{bp}$ ) for AA. For g.65812G $>$ A, digestion of the 148-bp PCR fragment with Tail resulted in a 221-bp product for the AA, 221, 187, and $34 \mathrm{bp}$ for the GA, and 187 and $34 \mathrm{bp}$ for the GG. For g.67492T $>\mathrm{G}$, Bse 11 digested 436-bp products and generated 1 fragment (436 bp) for the TT, 2 fragments (335 and $101 \mathrm{bp}$ ) for the GG, and 3 fragments $(436,335$, and $101 \mathrm{bp}$ ) for TG. For g.67519T $>\mathrm{C}$, the 436-bp products digested by Nco1 formed 1 fragment (436 bp) for TT, 2 fragments (364 and $72 \mathrm{bp}$ ) for CC, and 3 fragments $(436,364$, and $72 \mathrm{bp})$ for TC. For g.68964G $>\mathrm{A}$, the 382-bp products digested by $B s p A C 1$ formed 1 fragment ( $382 \mathrm{bp}$ ) for the GG, 2 fragments ( 340 and $42 \mathrm{bp}$ ) for AA, and 3 fragments $(382,340$, and $42 \mathrm{bp})$ for GA.

\section{Diversity analyses}

The genotypic frequencies and genetic diversity parameters $\left(H_{\mathrm{E}}\right.$ and PIC) of the 5 SNPs are presented in Table 2. The PIC was calculated for each locus, and the values ranged from 0.21 to 0.37 . According to the PIC calculation, our data showed that the cattle populations had intermediate genetic diversity at the 5 SNP loci, except for Jiaxian cattle populations in g.67519T $>$ C. This reflected the fact that there was not a very high genetic diversity within Chinese bovine STAT3 in the analyzed populations.

The Chi-square test showed that neither g.65812G $>$ A nor g.68964G $>$ A followed HWE, whereas the individual frequencies of the genotypes agreed were in HWE for other SNPs in Qinchuan cattle populations. For the Jiaxian cattle, the genotype distributions of the 4 mutations were in HWE except the g.67519T $>$ C. 


\section{Effect of the polymorphism locus on body measurement and carcass quality traits}

The association between STAT3 polymorphism and body measurement traits was analyzed, and the results are shown in Table 3. At the g. $43591 \mathrm{G}>$ A locus, the mean value of animals with genotype AA was significantly different from that of animals with genotype GG for the parameters body length and backfat thickness $(\mathrm{P}<0.01)$. Meanwhile, there was a significant difference between the AA and GG genotypes with withers height and chest circumference (P $<0.05$ ). At the g.65812G $>$ A locus, animals with genotype GA had significantly greater body length, chest circumference, and backfat thickness than those with genotype AA $(\mathrm{P}<0.05)$. At the g.67492T $>$ G locus, animals with genotype GG had significantly bigger loin muscle area as determined by ultrasound than those with genotype TT $(\mathrm{P}<0.01)$. At the g.67492T $>\mathrm{G}$ locus, animals with genotype $\mathrm{CC}$ had significantly greater body length and chest circumference than those with genotype TT $(P<0.05)$. Significant differences were found in backfat thickness between the 2 genotypes $(\mathrm{P}<0.01)$. At the g.68964G $>$ A locus, animals with genotype GA had significantly greater body length than those with genotype $\mathrm{AA}(\mathrm{P}<0.05)$. For backfat thickness, the AG genotype had a higher mean value than the AA genotype $\operatorname{did}(\mathrm{P}<0.01)$.

\begin{tabular}{|c|c|c|c|c|c|c|c|}
\hline Locus & Genotypes & $\mathrm{BL}(\mathrm{cm})$ & WH (cm) & $\mathrm{CC}(\mathrm{cm})$ & $\mathrm{BT}(\mathrm{cm})$ & $\operatorname{ULA}\left(\mathrm{cm}^{2}\right)$ & IMF $(\mathrm{cm})$ \\
\hline \multirow[t]{4}{*}{ g. $43591 \mathrm{G}>\mathrm{A}$} & GG (172) & $137.21 \pm 0.42^{\mathrm{Bb}}$ & $122.99 \pm 0.62^{b}$ & $43.19 \pm 0.26^{\mathrm{b}}$ & $0.75 \pm 0.01^{\mathrm{C}}$ & $63.49 \pm 0.64$ & $7.00 \pm 0.06$ \\
\hline & GA (103) & $142.15 \pm 0.54^{\mathrm{a}}$ & $125.30 \pm 0.57$ & $44.35 \pm 0.33$ & $0.91 \pm 0.01^{\mathrm{B}}$ & $63.37 \pm 0.81$ & $7.12 \pm 0.08$ \\
\hline & $\mathrm{AA}(96)$ & $145.82 \pm 0.57^{\mathrm{A}}$ & $127.97 \pm 0.60^{\mathrm{a}}$ & $45.00 \pm 0.35^{\mathrm{a}}$ & $1.33 \pm 0.02^{\mathrm{A}}$ & $65.38 \pm 0.86$ & $7.17 \pm 0.09$ \\
\hline & $\mathrm{P}$ & 0.001 & 0.032 & 0.021 & 0.000 & 0.067 & 0.123 \\
\hline \multirow[t]{4}{*}{ g. $65812 \mathrm{G}>\mathrm{A}$} & GG (205) & $140.96 \pm 0.44^{\mathrm{a}}$ & $125.14 \pm 0.43$ & $44.16 \pm 0.24^{\mathrm{a}}$ & $0.95 \pm 0.19^{\mathrm{a}}$ & $63.98 \pm 1.57^{\mathrm{b}}$ & $7.15 \pm 0.06$ \\
\hline & GA (131) & $141.94 \pm 0.55^{\mathrm{a}}$ & $125.21 \pm 0.54$ & $44.06 \pm 0.30^{\mathrm{a}}$ & $0.96 \pm 0.24^{\mathrm{a}}$ & $68.93 \pm 1.21^{\mathrm{a}}$ & $7.03 \pm 0.07$ \\
\hline & $\mathrm{AA}(35)$ & $135.45 \pm 1.07^{\mathrm{b}}$ & $122.43 \pm 1.04$ & $42.60 \pm 0.58^{b}$ & $0.82 \pm 0.47^{\mathrm{b}}$ & $64.41 \pm 2.22^{b}$ & $6.98 \pm 0.14$ \\
\hline & $\mathrm{P}$ & 0.036 & 0.157 & 0.036 & 0.011 & 0.018 & 0.212 \\
\hline \multirow[t]{4}{*}{ g. $67492 \mathrm{~T}>\mathrm{G}$} & ТT (140) & $139.69 \pm 0.55$ & $123.93 \pm 0.52$ & $43.35 \pm 0.29$ & $0.94 \pm 0.02$ & $63.67 \pm 1.10^{\mathrm{B}}$ & $7.04 \pm 0.07$ \\
\hline & TG (133) & $141.08 \pm 0.56$ & $125.64 \pm 0.53$ & $44.07 \pm 0.31$ & $0.93 \pm 0.02$ & $63.64 \pm 1.18^{\mathrm{B}}$ & $7.17 \pm 0.07$ \\
\hline & GG (98) & $141.97 \pm 0.66$ & $123.93 \pm 0.62$ & $44.76 \pm 0.35$ & $0.95 \pm 0.03$ & $71.65 \pm 2.71^{\mathrm{A}}$ & $7.04 \pm 0.09$ \\
\hline & $\mathrm{P}$ & 0.422 & 0.123 & 0.068 & 0.087 & 0.000 & 0.211 \\
\hline \multirow[t]{4}{*}{ g. $67519 \mathrm{~T}>\mathrm{C}$} & TT (44) & $137.34 \pm 0.97^{b}$ & $123.19 \pm 0.93$ & $42.66 \pm 0.52^{b}$ & $0.75 \pm 0.04^{\mathrm{B}}$ & $62.63 \pm 1.26$ & $7.02 \pm 0.13$ \\
\hline & $\mathrm{TC}(85)$ & $140.38 \pm 0.69$ & $124.35 \pm 0.66$ & $44.02 \pm 0.37$ & $0.90 \pm 0.03^{\mathrm{A}}$ & $64.55 \pm 1.11$ & $7.17 \pm 0.09$ \\
\hline & CC (242) & $141.57 \pm 0.41^{\mathrm{a}}$ & $125.41 \pm 0.39$ & $44.20 \pm 0.22^{\mathrm{a}}$ & $0.99 \pm 0.03^{\mathrm{A}}$ & $63.96 \pm 0.84$ & $7.07 \pm 0.06$ \\
\hline & $\mathrm{P}$ & 0.041 & 0.288 & 0.029 & 0.009 & 0.064 & 0.333 \\
\hline \multirow[t]{4}{*}{ g. $67964 \mathrm{G}>\mathrm{A}$} & GG (201) & $140.41 \pm 0.46$ & $124.73 \pm 0.43$ & $44.12 \pm 0.24$ & $0.90 \pm 0.02^{\mathrm{a}}$ & $64.63 \pm 0.59$ & $7.13 \pm 0.06$ \\
\hline & $\mathrm{GA}(140)$ & $142.04 \pm 0.55^{\mathrm{a}}$ & $125.63 \pm 0.58$ & $43.98 \pm 0.29$ & $1.02 \pm 0.02^{\mathrm{A}}$ & $63.40 \pm 0.70$ & $7.05 \pm 0.07$ \\
\hline & $\mathrm{AA}(30)$ & $137.55 \pm 1.18^{\mathrm{b}}$ & $122.73 \pm 1.11$ & $43.00 \pm 0.63$ & $0.80 \pm 0.05^{\mathrm{Bb}}$ & $61.79 \pm 1.52$ & $6.92 \pm 0.16$ \\
\hline & $\mathrm{P}$ & 0.029 & 0.320 & 0.117 & 0.000 & 0.072 & 0.291 \\
\hline
\end{tabular}

a,b Means with different superscripts are significantly different $(\mathrm{P}<0.05) .{ }^{\mathrm{A}, \mathrm{B}}$ Means with different superscripts are significantly different $(\mathrm{P}<0.01) . \mathrm{BL}=$ body length, $\mathrm{WH}=$ withers height, $\mathrm{CC}=$ chest circumference, $\mathrm{BT}=$ backfat thickness, ULA = ultrasound loin muscle area, and IMF = intramuscular fat.

\section{DISCUSSION}

During bovine breeding, body measurement and carcass traits are considered economically important, and are affected by many factors such as genotype, sex, age, breed, herd, location, and other random environment factors (Gui et al., 2014). Over the past 40 years, genetic improvement has been achieved by selection based on phenotypic information (Zhang et al., 2008). Presently, many genes have been identified to be involved in controlling growth (Liu et al., 2012b; Zhang et al., 2012), reproduction (Chu et al., 2010), and meat quality (Jiao et al., 2010; Li et al., 2013) in livestock. In addition, the STAT protein family is a group of 
transcription factors that are found in diverse organisms, ranging from flatworms to humans. In particular, STAT3 regulates diverse target pathways involved in bone formation (Zhou et al., 2011) and adipocyte differentiation (Priceman et al., 2013), which is important for body measurement and carcass quality traits in livestock.

The objective of the present study was to identify and characterize polymorphisms within the coding and non-coding regions of bovine STAT3 in 371 individual Qinchuan cattle. These SNPs (g.43591G $>$ A, g. 65812G $>$ A, g. 67492T $>$ G, g.67519T $>$ C and g.68964G $>$ A) were detected by PCR-RFLP and DNA sequencing. Our results showed that g.43591G $>A$ is associated with body length, withers height, chest circumference, and backfat thickness, and AA appears to be the beneficial genotype; both g.65812G $>$ A and g.67519T $>$ C are associated with body length, chest circumference, and backfat thickness, and the GG and CC genotype seems to be beneficial, respectively; g.68964G $>$ A is associated with body length and backfat thickness, and GA seems to be the beneficial genotype. Based on the results, we suggest that STAT3 has a potential effect on body measurement and carcass quality traits in Qinchuan cattle population.

Here, g.43591G $>$ A, g.67492T $>$ G, g.67519T $>$ C, and g.68964G $>$ A were identified in introns, and did not change the structure of the encoded proteins. Recently, however, studies have shown that intronic mutations may affect splice sites and consequently mRNA stability, and may lead to truncated or a lack of protein products (Ibeagha-Awemu et al., 2008). Importantly, further studies are needed to determine how the mutations affect phenotypic variation of these traits.

In conclusion, to our knowledge, this study is the first report of 5 SNPs in bovine STAT3. We analyzed their association with body measurements and carcass quality traits in a Qinchuan cattle population. Based on these results, it can be inferred that mutations in STAT3 affect economic traits and might be used as genetic marker for breeding beef cattle.

\section{Conflicts of interest}

The authors declare no conflict of interest.

\section{ACKNOWLEDGMENTS}

We extend special thanks to Prof. Zan for assistance. Research supported by the National “863” Program of China (\#2013 AA102505 and \#2011AA100307-02), the National Natural Science Foundation (\#31272411), the National Beef and Yak Industrial Technology System (\#CARS-38), the National Science-technology Support Plan Projects (\#2012BAD28B04-03), and the Technical Innovation Engineering Project of Shaanxi Province (\#2014 KTZB02-02$01)$.

\section{REFERENCES}

Chu MX, Zhao XH, Zhang YJ, Jin M, et al. (2010). Polymorphisms of BMPR-IB gene and their relationship with litter size in goats. Mol. Biol. Rep. 37: 4033-4039.

Darnell JE Jr. (1997). STATs and gene regulation. Science 277: 1630-1635.

Deng J, Hua K, Lesser SS and Harp JB (2000). Activation of signal transducer and activator of transcription-3 during proliferative phases of 3T3-L1 adipogenesis. Endocrinology 141: 2370-2376.

Derecka M, Gornicka A, Koralov SB, Szczepanek K, et al. (2012). Tyk2 and Stat3 regulate brown adipose tissue differentiation and obesity. Cell metab. 16: 814-824.

Dinasarapu AR, Gupta S, Ram Maurya M, Fahy E, et al. (2013). A combined omics study on activated macrophagesenhanced role of STATs in apoptosis, immunity and lipid metabolism. Bioinformatics 29: 2735-2743. 
Gough DJ, Corlett A, Schlessinger K, Wegrzyn J, et al. (2009). Mitochondrial STAT3 supports Ras-dependent oncogenic transformation. Science 324: 1713-1716.

Gui L, Wang H, Wei S, Zhang Y, et al. (2014). Molecular characterization, expression profiles, and analysis of Qinchuan cattle SIRT1 gene association with meat quality and body measurement traits (Bos taurus). Mol. Biol. Rep. 41: 52375246.

Ibeagha-Awemu EM, Kgwatalala P, and Zhao X (2008). A critical analysis of production-associated DNA polymorphisms in the genes of cattle, goat, sheep, and pig. Mamm. Genome 19: 591-617.

Jiao Y, Zan LS, Liu YF, Wang HB, et al. (2010). A novel polymorphism of the MYPN gene and its association with meat quality traits in Bos taurus. Genet. Mol. Res. 9: 1751-1758.

Levy DE and Darnell Jr JE. (2002). STATs: transcriptional control and biological impact. Nat. Rev. Mol. Cell Biol. 3: 651-662.

Li Y, Gao J, Yang N, Fu C, et al. (2013). The polymorphisms of LYRM1 gene and their association with body measurement and ultrasound traits of Qinchuan cattle. Mol. Biol. Rep. 40: 1511-1517.

Lidija K (2008). The role of signal transducers and activators of transcription in colon cancer. Front. Biosci. 13: 28882899.

Liu J, Jing X, Gan L and Sun C (2012a). The JAK2/STAT3 signal pathway regulates the expression of genes related to skeletal muscle development and energy metabolism in mice and mouse skeletal muscle cells. Biosci. Biotechnol. Biochem. 76: 1866-1870.

Liu Y, Zan L, Zhao S, Xin Y, et al. (2012b). Molecular characterization, expression pattern, polymorphism and association analysis of bovine ADAMTSL3 gene. Mol. Biol. Rep. 39: 1551-1560.

Priceman SJ, Kujawski M, Shen S, Cherryholmes GA, et al. (2013). Regulation of adipose tissue T cell subsets by Stat3 is crucial for diet-induced obesity and insulin resistance. Proc. Natl. Acad. Sci. U. S. A. 110: 13079-13084.

Schust J, Sperl B, Hollis A, Mayer TU, et al. (2006). Stattic: A small molecule inhibitor of STAT3 activation and dimerization. Chem. Biol. 13: 1235-1242.

Sen B, Saigal B, Parikh N, Gallick G, et al. (2009). Sustained Src inhibition results in signal transducer and activator of transcription 3 (STAT3) activation and cancer cell survival via altered Janus-activated kinase-STAT3 binding. Cancer Res. 69: 1958-1965.

Turkson J and Jove R (2000). STAT proteins: novel molecular targets for cancer drug discovery. Oncogene 19: 6613-6626.

Wang D, Zhou Y, Lei W, Zhang K, et al. (2010). Signal transducer and activator of transcription 3 (STAT3) regulates adipocyte differentiation via peroxisome-proliferator-activated receptor $\gamma(\operatorname{PPAR} \gamma)$. Biol. Cell 102: 1-12.

Yang J and George RS (2008). Roles of unphosphorylated STATs in signaling. Cell Res. 18: 443-451.

Zhang B, Zhao G, Lan X, Lei C, et al. (2012). Polymorphism in GHRH gene and its association with growth traits in Chinese native cattle. Res. Vet. Sci. 92: 243-246.

Zhang C, Zhang W, Luo H, Yue W, et al. (2008). A new single nucleotide polymorphism in the IGF-I gene and its association with growth traits in the Nanjiang Huang goat. Aust. J. Anim. Sci. 21: 1073-1079.

Zhang K, Guo W, Yang Y and Wu J (2011). JAK2/STAT3 pathway is involved in the early stage of adipogenesis through regulating $\mathrm{C} / \mathrm{EBPb}$ transcription. J. Cell. Biochem. 112: 488-497.

Zhou H, Newnum AB, Martin JR, Li P, et al. (2011). Osteoblast/osteocyte-specific inactivation of Stat3 decreases loaddriven bone formation and accumulates reactive oxygen species. Bone 49: 404-411. 